\title{
A Study of Mast Cell Tumours in Dogs
}

\author{
Surjeet Singh $^{1} *$, R.P. Gupta ${ }^{2}$, B.L. Jangir ${ }^{3}$ and Sapna Soni ${ }^{4}$ \\ Department of Veterinary Pathology, College of Veterinary Sciences, \\ Lala Lajpat Rai University of Veterinary and Animal Sciences, Hisar-125004, India \\ *Corresponding author:
}

\section{A B S T R A C T}

\begin{tabular}{|l|}
\hline Ke y w or d s \\
Dog, \\
Histopathology, \\
Cytology, \\
Mastocytoma
\end{tabular}

Seven cases of tumours were diagnosed as mastocytoma located on tail, ventral abdomen, left and right forelimb, left lower flank and thoracic area. Shape of the tumour was oval or round to diffuse and size varied from 3 to $12 \mathrm{~cm}$. The cytological examination of the impression smear stained with Giemsa revealed abundant mast cells, few lymphocytes and neutrophils. Histopathologically examination of the biopsy sample revealed sheets of neoplastic cells almost round in shape with distinct boundary of cytoplasm containing abundant granules and round to ovoid nuclei with mild to moderate amount of connective tissue stroma. In the present study, mastocytoma did not reveal any immunoreactivity to PCK-26 and Ki67.

\section{Introduction}

Canine develops neoplasm twice as frequently as humans. (Welle et al., 2008) reported that dogs have a unique risk of developing cutaneous mast cell tumours and they account for $7 \%$ to $21 \%$ of all canine skin tumours. Mast cell tumours are one of the most common tumour of canine skin and they are difficult to manage because of their variable clinical presentation and behaviour (Dobson et al., 2007). Mast cells, normal and neoplastic, contain and release important biologically active substances: heparin, histamine and proteolytic enzymes (Misdorp W., 2004, Noli et al., 2001). The aetiology of canine mast cell tumours (MCTs) is unknown but is probably multifactorial. There is no sex predilection but several breeds of dog including the boxer, Boston terrier, Labrador and golden retriever appear to be predisposed to development of this tumour. Most mast cell tumours are relatively easy to diagnose in routinely processed tissues because of their morphology and staining characteristics (Cannas et al., 1994). However studies in dogs particularly in immunohistochemical expression of cytokeratin (CK) and Ki67 in these tumours are sparse. Seven cases of tumours were diagnosed as mastocytoma located on tail, ventral abdomen, left and right forelimb, left lower flank and thoracic area. 
Shape of the tumour was oval or round to diffuse and size varied from 3 to $12 \mathrm{~cm}$. All these tumours were soft in consistency and cut surface appeared whitish pink to yellowish red in colour. Ulceration in three cases was also observed. The dogs had clinical history of anorexia, lameness and swelling with ulcers at the site of growth. Out of seven cases, four cases brought to Teaching Veterinary Clinical Complex, Lala Lajpat Rai University of Veterinary and Animal Sciences, Hisar and rest three biopsy collected from private pet clinics from Delhi and Chandigarh.

\section{Materials and Methods}

A piece of tissue was collected and fixed in $10 \%$ neutral buffered formalin for histopathological examination and immunohistochemistry. After proper fixation, the tissue was washed in running tap water for overnight, dehydrated in ascending grades of ethanol, cleared in benzene and processed for paraffin embedding as per the conventional procedure. The paraffin embedded tissues were cut into $4 \mu \mathrm{m}$ thick sections and stained with Haematoxylin and Eosin as per routine procedure (Luna, 1968). For immunohistochemistry, $4 \mu \mathrm{m}$ thick sections were mounted on 3-aminopropyl triethoxysaline (APES) coated slides. Sections were deparaffinized in xylene and brought to water through descending gradients of ethanol. Antigen retrieval was done by the microwave oven method in citrate buffer $(\mathrm{pH}$ 6.0) for 30 minutes. Immunohistochemistry was performed as per protocol (Sharma S., 2015), with modification in quenching of endogenous peroxidase with $3 \%$ hydrogen peroxide in methanol. Primary monoclonal antibodies for cytokeratin (Anti pancytokeratin, clone pck-26, Sigma Chemicals, USA) and Ki67 (anti-Ki67, clone MIB-1, Santa Cruz, USA) were used at the dilution of 1:100 and undiluted, respectively. Secondary antibody was used at the dilution of 1:20 in PBS containing $1 \%$ bovine serum albumin (BSA; Sigma Chemicals, USA). Positive and negative controls were included in all reactions. The slides were screened under microscope for immunostaining reaction.

\section{Results and Discussion}

The cytological examination of the impression smear stained with Giemsa revealed abundant mast cells, few lymphocytes and neutrophils (Fig. 1-4).

Fig.1 Mastocytoma: Round intact growth on fore limb

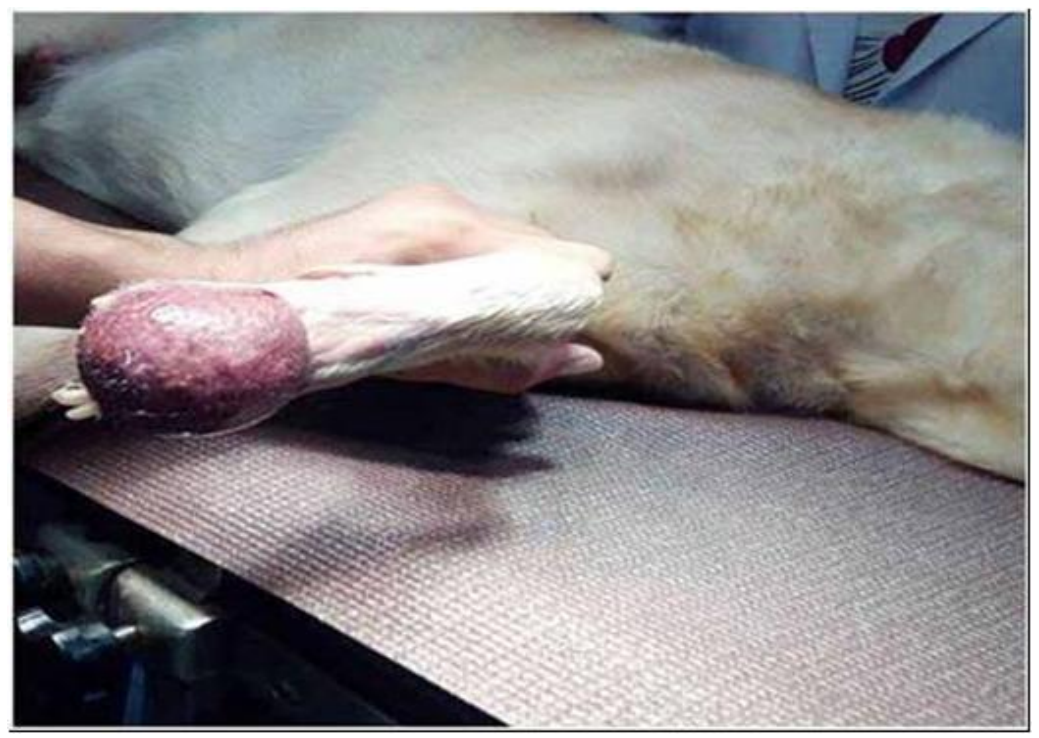


Fig.2 Mastocytoma: Cut surface appeared yellowish red in colour having soft consistency

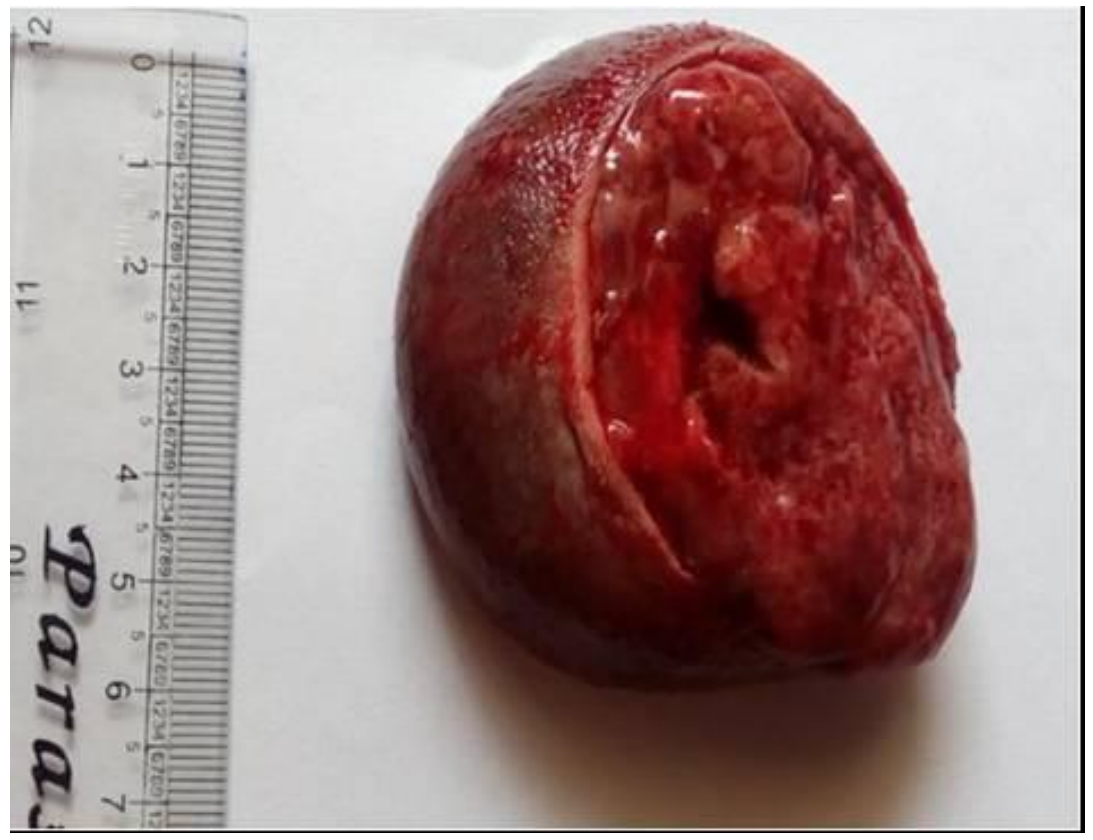

Fig.3 Mastocytoma: Photomicrograph showing round neoplastic cells with eosinophilic cytoplasm and centrally located hyperchromatic nuclei along with eosinophilic infilteration. $\mathrm{H} \& \mathrm{E} \times 200$

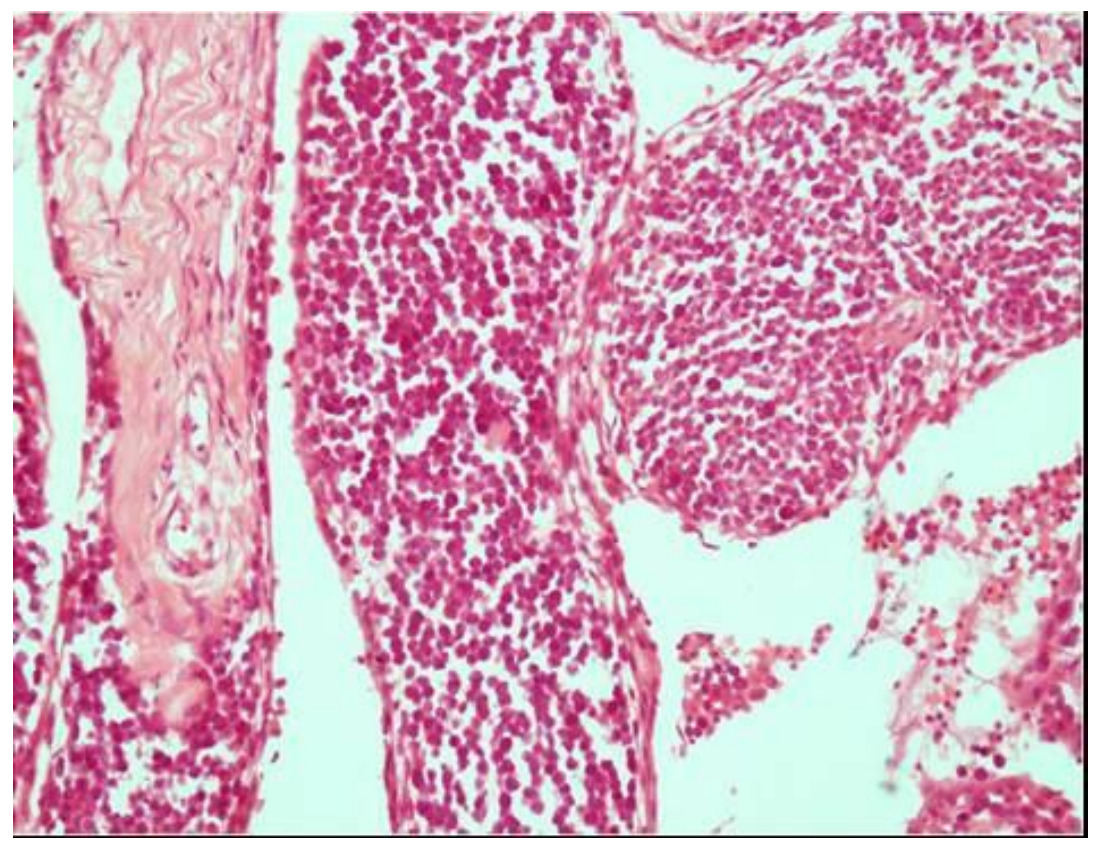


Fig.4 Mastocytoma: Photomicrograph of impression smear showing metachromatic granules in the cytoplasm as well as outside the cell. Giemsa staining $\times 1000$

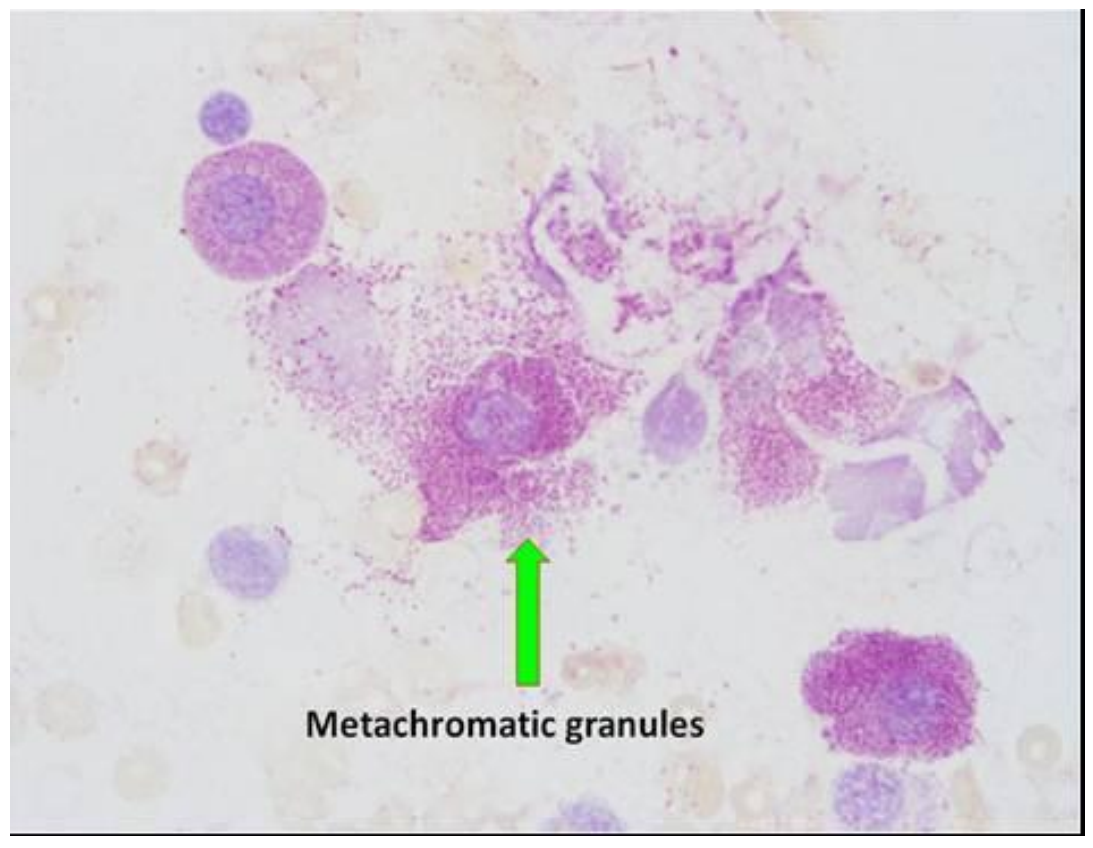

Histopathologically examination of the biopsy sample revealed sheets of neoplastic cells almost round in shape with distinct boundary of cytoplasm containing abundant granules and round to ovoid nuclei with mild to moderate amount of connective tissue stroma.

Duplicate sections stained with toluidene blue revealed more prominent granules which stained purple and nuclei stained blue. These characteristics features of mastocytoma were almost same as described by (Kujur et al., 2005). Cutaneous mastocytoma observed in the present finding did not reveal any metastasis. Mastocytoma are considered as one of the aggressive tumours in dogs and grow very quickly (Grano et al., 2012). Tumour growth present on ventral abdomen and thoracic region was characterized by group of round neoplastic cells in small number along with eosinophils in the dermis. These cells were also seen in between skeletal muscle bundles along with connective tissue stroma. Large blood vessels filled with RBC were also noticed in connective tissue stroma.
In the present study, mastocytoma did not reveal any immunoreactivity to PCK-26 and Ki67. Canine mastocytomas may be used as animal model of a human disease and as such, familiarity with their cytologic and histopathologic presentation may be useful for recognizing mast cell prolifertion in humans (Fulciniti et al., 2007).

\section{Acknowledgements}

Authors are thankful to Director, Teaching Veterinary Clinical Complex, LUVAS, Hisar for providing biopsy samples.

\section{References}

Cannas Simoes, J.P. and Schoning, P. 1994. Canine mast cell tumours: a comparison of staining techniques. $J$. Vet. Diagn. Invest. 6: 458-465.

Dobson, J.M. and Scase, T.J. 2007. Advances in the diagnosis and management of cutaneous mast cell tumours in dogs. J. Small. Animal. Pract. 48(8): 424- 
431.

Fulciniti, F., Di Mattia, D., Curcio, M.P., Bove, P., Rota, A.M. and Botti, G. 2007. Canine Mastocytoma. Acta Cytologica 51: 616-620.

Grano, F.G., Silva, J.E.S., Melo, G.D., Schweigert, A., Ciarlini, P.C. and Machado, G.F. 2012. Visceral mast cell tumor and mastocythemia in a dog. Braz. J. Vet. Pathol. 5(3): 142145.

Kujur, R.F., Sudhakar Rao, G.V., Balachandran, V. and Murali Manohar, B. 2005. Cytological and histopathological diagnosis of mast cell tumours in canine. Indian J. Vet. Pathol. 29(2): 146-147.

Luna, L.G. 1968. Manual of Histologic Staining Methods of Armed Forces Institute of Pathology. $3^{\text {rd }}$ Ed.
McGraw Hill Book Co. New York.

Noli, C. and Miolo, A. 2001. The mast cell in wound healing. Vet Dermatol 12: 303313.

Misdorp, W. 2004. Mast cells and canine mast cell tumours. A review. Vet $Q$ 26(4):156-169.

Sharma, S. 2015. Pathobiological studies on bovine neoplasms with special reference to epithelial tumours. M.V.Sc. Thesis (Veterinary Pathology), Lala Lajpat Rai University of Veterinary and Animal Sciences, Hisar, Haryana.

Welle, M.M., Bley, C.R., Howard. J. and Rufenacht, S. 2008. Canine mast cell tumours: a review of the pathogenesis, clinical features, pathology and treatment. Vet Dermatol 19(6): 32139.

\section{How to cite this article:}

Surjeet Singh, R.P. Gupta, B.L. Jangir and Sapna Soni. 2018. A Study of Mast Cell Tumours in Dogs. Int.J.Curr.Microbiol.App.Sci. 7(08): 2696-2700.

doi: https://doi.org/10.20546/ijcmas.2018.708.281 